\title{
Intersections between Sexual Identity, Sexual Attraction, and Sexual Behavior among a Nationally Representative Sample of American Men and Women
}

\author{
Emma Mishel $^{1}$
}

\begin{abstract}
Social scientists struggle on how to best operationalize and measure sexual orientation. Depending on the survey, researchers can use self-reports of lesbian, gay, or bisexual (LGB) identity, same-sex partner cohabitation, same-sex sexual attraction, or same-sex sexual behavior. All measures come with their own limitations. To illuminate differences in these measures, this study examines the intersections between self-reported sexual identity, attraction, and behavior among a nationally representative sample of US men and women aged 15-45. I explore how and when the three measures align, examine the determinants of self-identifying as gay or bisexual based on sexual behavior and attraction, and assess gender differences in the patterns. I find that about $20 \%$ of women and $10 \%$ of men aged 15-45 would comprise the LGB community if it were defined to include those who report at least one of the following: gay or bisexual identity, any same-sex attraction, or same-sex sex in the last year. This is much higher than the $6.4 \%$ of women and 3.6\% of men aged $15-45$ who selfidentify as LGB. I conclude with recommendations that can aid in measurement of the LGB population, and discuss implications for using certain measures over others when conducting research on the LGB community.
\end{abstract}

Key words: Sexual orientation; sexuality; gay; population; quantitative.

\section{Introduction}

Much research on sexual minorities in the United States is qualitative due to challenges of collecting quantitative data on the lesbian, gay, and bisexual (LGB) population. One challenge is that questions about sexual orientation are not always asked in large, nationally representative surveys. Another is that, of the national surveys that do ask about sexual orientation, measures are not always consistent, and some surveys include more than one measure. For example, the concept of sexual orientation involves three main elements: the label we attach to our sexuality (sexual identity), the gender of those whom we engage in sexual activity (sexual behavior), and the gender of those whom we experience attraction to (sexual attraction). Researchers must thus select which measure(s) to use as their indicator of the LGB community - sometimes a crucial decision, as research results may differ depending on the measure used. An additional challenge is that responses to questions of this nature can be especially vulnerable to response bias.

\footnotetext{
${ }^{1}$ New York University, 295 Lafayette St $4^{\text {th }}$ Floor, New York, New York, 10012, U.S.A. Email: emmamishel@nyu.edu

Acknowledgments: I gratefully thank Paula England, Mike Hout, and David Greenberg for their helpful feedback, as well as the editors of Journal of Official Statistics for their helpful comments.
} 
Since operationalizing and defining sexual orientation is very complex, how to best estimate the size of the LGB population is also difficult. However, accurate measurement of the LGB population is vital, as researchers use these estimates to study inequalities between heterosexuals and LGB individuals across dimensions such as urban amenities, health, fertility and morbidity, educational attainment and investment, economic earnings, and household divisions of labor (e.g., Baumle et al. 2009; Berg and Lien 2002; Black et al. 2002; Black et al. 2003; Carpenter 2009; Harper 2007). Psychologists, evolutionary biologists, and geneticists also use these estimates in their respective fields (e.g., Cochran et al. 2003; Gavrilets and Rice 2006), and policy-makers take these estimates into account when assessing civil rights arguments and non-discrimination bills.

Using a self-identification measure to estimate the size of the lesbian, gay, and bisexual community, researchers from the Williams Institute have suggested that LGB individuals make up about $3.5 \%$ of the U.S. population (Gates 2011). Yet, self-identifying as lesbian, gay, or bisexual may put one at risk for employment discrimination (Tilcsik 2011; Mishel 2016), housing discrimination (Friedman et al. 2013), as well as at risk for being subjected to negative social stigmas by others, specifically surrounding one's own morality and competency (Mize and Manago 2018a; Webster et al. 1998). Thus, it is likely that not all Americans who feel some same-sex attraction, or who engage in same-sex sexual activity, also identify as lesbian, gay or bisexual, and this may translate into not marking it on a survey.

In this vein, this study analyzes the links between the three commonly used measures of sexual orientation: sexual identity, sexual attraction, and sexual behavior, using a nationally representative sample of the United States. Specifically, I pool four waves of a nationally representative dataset of U.S. men and women aged 15-45, and explore the a) patterns and links between self-reported sexual identity, attraction, and behavior, b) determinants of self-identifying as lesbian, gay, or bisexual based on self-reported sexual behavior and sexual attraction, and c) gender differences in these patterns. Based on the findings, I put forth arguments for using certain measures over others when conducting research on the LGB community, and I provide recommendations that can aid in measurement and analysis of the LGB population. In all, this research seeks to shed light on the complexity of defining, measuring, and operationalizing sexual orientation, while providing insights that can help researchers in conducting quantitative data analysis on the LGB population.

\section{Past Research}

To conduct research on the LGB population, researchers must make an important decision about the specific measure they choose to use as their indicator of LGB identity. Some studies use self-identification as lesbian, gay, or bisexual as their measure (e.g., Carpenter and Eppink 2017; Cochran et al. 2003); others use reports of same-sex sexual behavior, either recently or ever (e.g., Badgett 1995; Berg and Lien 2002; Black et al. 2003); some use reports of same-sex sexual attraction (e.g., Busseri et al. 2006); others use reports of same-sex partner cohabitation (e.g., Baumle and Poston 2011; Fischer 2016); and yet others use a combination of one or more of these measures (e.g., Bostwick et al. 2010; England et al. 2016; Mize 2016). The decision of which measure to use is critical, as past 
studies show disjunctures between a person's self-described sexual identity and with whom the individual engages in sexual behavior, or to whom the individual is sexually attracted (Epstein et al. 2012; Igartua et al. 2009; Kinsey et al. 1953; Laumann et al. 1994), and these disjunctures have been shown to change research results, depending on the measure of sexual orientation used (Bostwick et al. 2010; Compton et al. 2015; Korchmaros et al. 2013; Mize 2016).

To understand the correlations between sexual identity, sexual desire, and sexual behavior, previous studies conducted in the United Kingdom and Australia have used nationally representative, country-specific data to analyze the patterns between the three measures among its citizens (e.g., Geary et al. 2018; Richters et al. 2014; Smith et al. 2003; Wellings et al. 1994). For Australian men and women, same-sex attraction and same-sex sexual behavior were more common than gay or bisexual identity would suggest (Richters et al. 2014; Smith et al. 2003), and similar results were found in the United Kingdom (Geary et al. 2018; Wellings et al. 1994).

Past studies based in the United States have examined patterns between sexual identity, attraction, and behavior as well (e.g., Laumann et al. 1994). The more recent studies to do so have either used smaller and unrepresentative samples, such as adolescents/young adults from one Southwestern city (Korchmaros et al. 2013), young women (Diamond 2008), men from New York City (Pathela et al. 2006), or have focused on bisexuality (Compton et al. 2015), asexuality (Poston and Baumle 2010), or on health risks for the LGB community (Bostwick et al. 2010). Two reports from the Center for Disease Control's National Health Statistics Department use nationally representative data of the United States to give a cursory glance at the links between sexual behavior, attraction and identity (Chandra et al. 2011; Copen et al. 2016). However, these reports do not go beyond mere descriptive tables, and with their focus on heterosexual behavior, they are not able to list values in many figures pertaining to non-heterosexual identity, same-sex sexual behavior, or different levels of same-sex attraction due to small sample size.

This research builds upon previous studies by pooling four waves of a large representative sample of U.S. men and women aged 15-45 to examine the links between sexual identity, sexual attraction, and sexual behavior. I go beyond descriptive statistics to estimate relationships using regression analysis, which allows me to control for important demographic characteristics when assessing these patterns. I also examine gender differences in patterns, and discuss implications for using different measures of sexual orientation. I conclude by discussing which measure(s) of sexual orientation may be most useful depending on the research objectives, and by discussing how this analysis has policy implications, as estimates for and research on the LGB community are used to inform a host of different research fields.

\section{Data and Measures}

I use the National Survey of Family Growth (NSFG) to conduct this research. The NSFG is a nationally representative survey of the U.S. household population, with in-person interviews conducted with men and women between 15 and 45. The survey collects information on family life, marriage and divorce, pregnancy, infertility, use of contraception, 
health, and sexuality. The NSFG uses three measures of sexual orientation: sexual identity, sexual attraction, and sexual behavior, which allows me to compare responses from all three variables. To obtain the largest sample size of sexual minorities, I pool data from four NSFG survey waves: 2002, 2006-2010, 2011-2013, and 2013-2015. In wave 2002, 7,643 women and 4,928 men (12,571 in total) were sampled; in wave 2006-2010, 12,279 women and 10,403 men (22,682 in total) were sampled; in wave 2011-2013, 5,601 women and 4,815 men (10,416 in total) were sampled; and in wave 2013-2105, 5,699 women and 4,506 men (10,205 in total) were sampled, making my total sample size 55,874. All analyses were conducted using the designated weights from NSFG. As such, results in all tables and figures reflect the general U.S. population among those aged 15 to 45 . Participants were included in analysis if they answered specific items that assessed sexual identity, sexual attraction, and sexual behavior measures, as well as relevant demographic measures, for each table and regression in question; if not, they were excluded from the analysis. Below, I describe how I operationalize each sexual orientation measure, and provide details on NSFG's question ordering and relevant pathways.

\subsection{Sexual Orientation Measures}

\subsubsection{Sexual Identity}

To assess sexual identity, I use a question that asked respondents whether they see themselves as "heterosexual or straight," "homosexual, gay, or lesbian," or "bisexual." Note that for brevity, and to facilitate comparing analyses across genders, I use the term "gay" when referring to the men and women who marked "homosexual, gay, or lesbian." I use the term "straight" when referring to the men and women who marked "heterosexual or straight." In the 2002 wave and part of the 2006-2010 wave (through June 2008), respondents were also given the option of choosing "something else" to describe their sexual identity; and, in every wave except 2002, respondents were also given the option of choosing "don't know" to describe their sexual identity. Thus, I create a fourth category, "something else/ don't know," which combines these two additional sexual identity options across survey waves. I include and combine "something else" and "don't know" sexual identities, as I believe it is important to get a sense of the proportions of individuals who do not select one of the standard sexual identities when other options are given.

\subsubsection{Sexual Attraction}

To assess attraction I use the following question in the NSFG: "People are different in their sexual attraction to other people. Which best describes your feelings? Are you..." Male respondents were then shown categories for: only attracted to females, mostly attracted to females, equally attracted to males and females, mostly attracted to males, and only attracted to males. Response options for women were the same, but the gender order was reversed. Thus, I coded attraction on a five-point scale, as follows: only attracted to the other sex, mostly attracted to the other sex, equal attraction to both sexes, mostly attracted to the same sex, and only attracted to the same sex.

Please not that throughout this article, I use the term "other sex" rather than "opposite sex" when referring to women in relation to men and vice versa, because men and women 
are not the opposite of each other. When referring to women reporting sex with women, and men reporting sex with men, I use the term "same-sex" to describe the sexual behavior. I prefer language that refers to an other sex rather than the other sex so as not to imply that there are only two sexes, given that some individuals identify as nonbinary. However, the NSFG provided only "male" or "female" as categories for respondents and their sex partners, so in these data male is the only other sex choice for women and vice versa. Thus, I use language consistent with the limitations of the data.

\subsubsection{Sexual Behavior}

I include measures for lifetime and recent sexual behavior using the following questions: "Thinking about your entire life, how many [male/female] sex partners have you had?" and "Thinking about the last 12 months, how many [male/female] sex partners have you had?" I operationalize these variables to assess whether someone had ever had a same-sex sex partner ( 0 for no, 1 for yes), and whether they had one in the last year ( 0 for no, 1 for yes). I also use these measures to assess how many same-sex sex partners they have ever had, and had in the last year, coded as follows: $0,1,2-4$, or 5 or more. Lastly, I include a measure of whether the respondent has had sex partners of both sexes, both ever and in the last year (0 for no, 1 for yes).

\subsection{NSFG's Survey Design and Question Pathways}

In this section, I describe the question pathways for the relevant sexual orientation measures. Women were first asked if they have ever performed oral sex on, or received oral sex from, another female. If they said no, they were then asked if they had "ever had any type of sexual experience of any kind with another female." If they said yes to any of these questions, they were then asked about their number of female sex partners ever, and in the last year. (If they said no to any of the questions above, they were assumed to have no same-sex sex partners.) Then, women were asked about their sexual attraction towards men and women, and about their sexual identity. Men were first asked if they have ever had oral or anal sex with another male, either given or received. If they answered yes to any of these questions, they were then asked about their number of male sex partners ever, and in the last year. (If they said no to any of the questions above, they were assumed to have no same-sex sex partners.) Then, men were asked about their sexual attraction towards women and men, and about their sexual identity.

Note that, as indicated above, the pathways used to screen respondents for questions about same-sex sex partners were slightly different for men and women. At first glance, NSFG seems to have created a higher bar for men to report a same-sex sex partner compared to women. That is, men weren't asked how many male sex partners they had had (and thus were assumed to have had none) unless they said they had oral or anal sex with a man, whereas women could be classified as having had sex with a woman if they said they had had "any" sexual experience with a woman, even if they did not report having had oral sex with a woman. Recent attention to the prevalence of women kissing women on dance floors and at parties (Rupp et al. 2014; Hamilton 2007) raises the question of whether women reporting sexual experience with women are referring to experiences such as these, or to more private sexual contact involving genitals. In analyses not shown, I ascertained 
that $88 \%$ of the women who said they had sex with a woman in the last year (regardless of whether they also said they had sex with a man) also reported that they had ever had oral sex with a woman, as did $86 \%$ of (the overlapping group of) women who reported having sex with both men and women in the last year. This suggests that the vast majority of those who say they have had a female sex partner have had private sexual experiences with women beyond kissing. Thus, I am relatively unconcerned that the measures artifactually create a higher bar for men than for women reporting on sexual behavior.

For questions deemed particularly sensitive by NSFG, Audio Computer-Assisted SelfInterview (ACASI) was used, which enables respondents to answer questions privately that is, without the interviewer seeing their response. Questions about sexual identity, behavior, and attraction were asked in the ACASI portion of the survey, which came at the very end of the NSFG survey. Other questions included in the ACASI part of the survey were about issues such as household income, unemployment, getting expelled from school, drug use, HIV/STDs, and experiences of sexual assault. Use of ACASI may reduce reporting bias on sensitive questions compared to other surveys that do not use this approach (Betts 2009; O'Reilly et al. 1994; Villarroel et al. 2006; Tourangeau and Smith 1996). Overall, NSFG reports that response rates for their recent data releases are around 69\% (Centers for Disease Control 2018).

\section{Analytical Approach}

\subsection{Descriptive Statistics}

I perform several analyses to examine the links between sexual identity, sexual attraction, and sexual behavior. First, I provide descriptive statistics of men's and women's selfreported sexual identity by self-reported sexual attraction and various sexual behaviors. Then, I assess whether there are statistically significant gender differences in these estimates by performing standard two-tailed t-tests. Following this, I examine the selfreported sexual attraction levels and sexual identities of men and women who report having had same-sex sex in the past year. These analyses all help to illuminate the patterns and links between sexual identity, attraction, and behavior among men and women aged 15-45 in the United States, and to assess whether there are gender differences in these patterns.

\subsection{Regression Analysis}

After analysis of the descriptive statistics, I move to regression analysis. I estimate eight logistic regression models that predict bisexual identity (four for women and four for men) and eight logistic regression models that predict gay identity (four for women and four for men). The dependent variable is either bisexual identity (compared to not bisexual identity) or gay identity (compared to not gay identity). The four main predictors are: (1) self-reported sexual attraction on a five-point scale, (2) whether the individual has ever had same-sex sex, (3) whether the individual has had partners of both sexes in the past year, and (4) whether the individual has had only same-sex sex partners in the past year. Each regression also controls for race, age, age-squared, mother's education, immigrant status, and metropolitan area, as well as survey wave. These regression models seek to assess how certain sexual behaviors and sexual attraction levels predict whether a man or woman age 
15-45 takes on a gay or bisexual identity. Such analysis helps to illuminate the links between sexual identity, attraction, and behavior; and, it goes beyond descriptive statistics in a useful way, as it predicts when someone may take on a gay or bisexual identity arguably the most common measure for counting the LGB population - after controlling for important demographic characteristics.

\subsection{Predicted Probabilities}

Calculated from the regression results, I plot the predicted probabilities for identifying as gay or bisexual, separately for men and women. I first plot the predicted probabilities corresponding to the four logistic regression models predicting bisexual identity, and then plot the predicted probabilities corresponding to the four logistic regressions predicting gay identity, separately for men and women. Predicted probabilities were obtained using an average marginal effects (AME) approach, and they are adjusted for race, mother's education, immigrant status, metropolitan city, and survey wave. Each plotted predicted probability includes bars to indicate confidence intervals at the $95 \%$ level.

\section{Results}

Table 1 displays the proportion of men and women who identify as straight, bisexual, gay, and something else/don't know. Table 1 also displays the proportions of men and women who have engaged in same-sex sex (such as whether they have ever had a same-sex sex partner, whether they have had partners of both sexes within the last year or ever, whether they have had only same-sex partners in the past year, and the number of same-sex partners they have ever had and had in the past year), as well as their self-reported sexual attraction level, by sexual identity. When examining women's self-reported sexual identities, Table 1 shows that overall, $92.2 \%$ of the 30,861 women identify as straight, $4.9 \%$ as bisexual, $1.5 \%$ as gay, and $1.4 \%$ said either something else or don't know. When examining the self-reported sexual identities of men, Table 1 shows that $95.1 \%$ of the 24,357 men identify as straight, $1.7 \%$ as bisexual, $1.9 \%$ as gay, and $1.3 \%$ said something else or don't know.

The estimates for those who identify as gay or bisexual are slightly larger here compared to the proportion of people who identify as gay or bisexual in the United Kingdom and Australia (see Geary et al. 2018; Richters et al. 2014); however, this is to be expected with a younger sample, as NSFG only sampled Americans aged 15-45 while the United Kingdom sampled adults aged 16-74 and Australia sampled adults aged 16-69. Indeed, many studies show that younger individuals are more likely to identify as non-heterosexual compared to older individuals (see Bridges and Moore 2018; England et al. 2016; Mishel et al. forthcoming).

Table 1 also shows that there are many gender differences when assessing how men and women age 15-45 label their sexual orientation: significantly more women than men identify as bisexual, and significantly more men than women identify as gay. This pattern is also seen in data from Australia (Richters et al. 2014) and the United Kingdom (Geary et al. 2018), and is consistent with past research in the United States (England et al. 2016; Gates 2011; Korchmaros et al. 2013). 


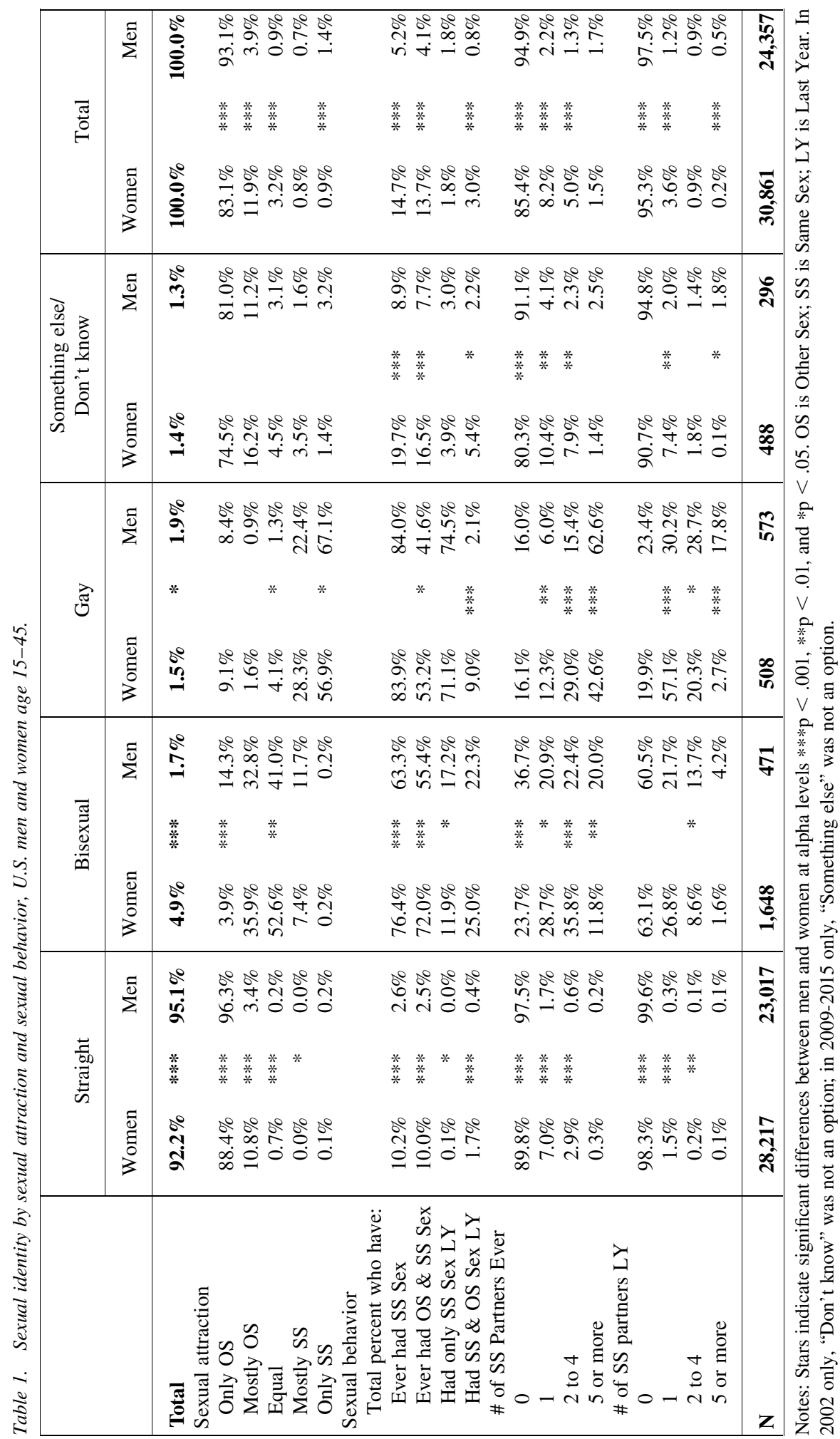




\subsection{Sexual Identity by Sexual Attraction}

How does sexual identity relate to sexual attraction among U.S. men and women aged 15-45? Table 1 shows some results that may be different from what one might expect. For example, Table 1 shows that about $9.1 \%$ of gay women, $3.9 \%$ of bisexual women, $8.4 \%$ of gay men, and $14.3 \%$ of bisexual men report that they are only attracted to the other-sex. In addition, over $11 \%$ of self-identified straight women report some level of same-sex attraction, while a smaller percentage of straight men (about 3.7\%) report the same. Furthermore, only $56.9 \%$ of self-identified gay women report only same-sex attraction, while $67.1 \%$ of gay men report the same.

Some of these disjunctures may be surprising. For example, if an individual identifies as gay or bisexual, surely they have some level of same-sex attraction. Indeed, this disjuncture is also found among Australian men and women (about $6 \%$ of self-identifying Australian gay women reported only sexual attraction to men, and about $2 \%$ of selfidentifying Australian gay men reported only sexual attraction to women) (Richters et al. 2014). Why someone who identifies as gay or bisexual does not report any same-sex attraction can only be speculated. One possible reason for this disjuncture is simple measurement error. Indeed, DeMaio et al. (2013) show that measurement error can be a big issue when conducting research on the LGB population; they find that about $28 \%$ of reported same-sex couple households in the 2010 Census are likely to be other-sex couple households, where either the man or woman was wrongly coded as the other gender (and as a result, the 2010 Census has now issued a "preferred" set of state-level estimates of same-sex couples, which are much lower). Other researchers also conclude that the number of same-sex married couples reported in the 2010 Census is likely inflated because gender was mismarked (e.g., Black et al. 2007; O'Connell and Gooding 2006). Coding errors, while not typically a big problem in probability-based analyses, can be a serious issue when analyzing a numerically small group of people, such as those who identify as LGB. While miscoding of gender is not very likely in analysis of NSFG data, since men and women were given different ACASI surveys that asked gender-specific questions about pregnancy and genitalia (see Section 3.2), it is nonetheless possible that responses to other questions were miscoded.

Besides attributing this disjuncture to coding errors, it may also be the case that the respondent did not understand either the sexual identity question or the attraction question, or both. After taking a closer look at the individuals who report gay identity and only othersex attraction in the NSFG, these respondents are disproportionately immigrants $(37 \%$ immigrant, compared to $15.6 \%$ of the entire sample); have less education compared to the entire sample (35\% did not graduate high school compared to $21 \%$ in the entire sample), and are less likely to be white (37\% white, compared to $60 \%$ white in the entire sample) (analysis not shown). This may suggest that some of these respondents did not understand one or both of the questions due to a language or cultural barrier. However, when analyzing the sexual behavior of these same respondents, $31 \%$ indicate that they have had same-sex sex, compared to just $10 \%$ of the entire sample who reported same-sex sex. This suggests that there may be more going on than respondents simply misunderstanding the question or marking the wrong answer. In other words, perhaps some individuals legitimately do not feel attracted to members of the same sex, but still identify with a gay or bisexual label for 
whatever reason - one possible reason being that they engage in same-sex sex. In any case, whether due to measurement error or due to unique and complex cases of how people align their sexual identity with their sexual attraction and sexual behavior, this finding is indeed puzzling, and it motivates further research perhaps using qualitative methods.

Other disjunctures in Table 1 may be less surprising. For example, Table 1 shows that $11.6 \%$ of self-identified straight women age 15-45 report some level of same-sex attraction, as do about $3.7 \%$ of self-identified straight men age 15-45. The fact that there are some Americans who feel same-sex attraction but do not identify as gay or bisexual is not surprising, as perhaps they do not feel strongly enough about it to identify as anything other than straight, or are dissuaded from doing so due to the potential for experiencing stigma or discrimination (Friedman et al. 2013; Herek 2009; Mishel 2016; Tilcsik 2011).

Table 1 also shows that about $43 \%$ of self-identified gay women report some level of other-sex attraction, as do about $33 \%$ of self-identified gay men. If we think of sexuality as being on a spectrum, one might assume that gay men and women are only attracted to the same sex, while straight men and women are only attracted to the other sex. This seems to be the case for most straight men and women, as an overwhelming majority of straight women and men age 15-45 report only other-sex attraction (88\% of women and $96 \%$ of men). However, sexual attraction levels for gay women and men aged 15-45 seem to be much more flexible: only $57 \%$ of gay women and $67 \%$ of gay men report only same-sex attraction. Results in Table 1 also reveal that self-identified straight women are significantly more likely to report same-sex attraction compared to self-identified straight men.

\subsection{Sexual Identity by Sexual Behavior}

How does sexual identity relate to sexual behavior for US men and women aged 15-45? Again, we see some disjunctures, and some significant gender differences. First, Table 1 shows that over $10 \%$ of self-identified straight women and $2.6 \%$ of self-identified straight men report having had same-sex sex sometime in their life. Furthermore, about $9 \%$ of selfidentified gay women have had both male and female sex partners in the past year, while about $2.1 \%$ of gay men report the same. Of course, it is important to note that these reported sexual experiences could simply be a result of previous sexual exploration, since the survey is measuring current sexual identity and current sexual attraction, but asking about past sexual behaviors. In addition, just because someone engages in sexual behavior with a certain gender does not mean that they identify with a sexual identity that is consistent with that behavior, nor does it automatically mean that they feel attracted to that particular gender; sexual preferences and/or identities may change over time (Diamond 2008).

The gender differences on these estimates are statistically significant, such that significantly more self-identified straight women than straight men report having had same-sex sex sometime in their life, and significantly more self-identified gay women than gay men report having both male and female sex partners in the last year. Among those who identify as bisexual, $76.4 \%$ of women report having had same-sex sex sometime in their life, compared to $63.3 \%$ of men - again a statistically significant difference. Among all men and women age 15-45 in the United States, about $15 \%$ of women report having had same-sex sex sometime in their life, as do about $5 \%$ of men - also a significant difference by gender. 
Interestingly, Table 1 shows that a large proportion of self-identified bisexual and gay individuals aged 15-45 have had 0 same-sex sex partners: about $16 \%$ of self-identified gay men and $16 \%$ of self-identified gay women report 0 same-sex sex partners, as do about $23.7 \%$ of self-identified bisexual women and about $36.7 \%$ of self-identified bisexual men. (In comparison, only about $12 \%$ of straight men and about $12 \%$ of straight women report 0 lifetime other-sex sex partners.) When assessing the number of same-sex sex partners for those who identify as gay or bisexual, Table 1 shows that gay and bisexual men report significantly more lifetime same-sex sex partners compared to gay and bisexual women. For example, $62.6 \%$ of gay men report five or more lifetime same-sex sex partners compared to just $42.6 \%$ of gay women, as do $20 \%$ of bisexual men compared to just $11.8 \%$ of bisexual women - both significant differences. Along the same lines, significantly more self-identified gay and bisexual women report just one lifetime same-sex sex partner compared to gay and bisexual men.

\subsection{Other Sexual Minority Identities}

Table 1 also shows that, relative to the number of persons who identified as gay or bisexual, a sizeable portion of both men and women age 15-45 identified as something else or don't know. About $1.3 \%$ of men marked something else or don't know, compared to $1.7 \%$ men who marked bisexual and $1.9 \%$ who marked gay. About the same proportion of women marked something else or don't know (1.4\%) as those who marked gay (1.5\%). Selecting a non-normative identity could be a sign of resistance against traditional sexual identification categories, as more and more individuals who report same-sex attraction or same-sex sexual behavior are taking on other identities, such as "queer." Rejection of normative sexual identity categories (i.e., gay, lesbian, bisexual) and adoption of other identity categories (i.e., queer, pansexual) has been shown to occur more among younger individuals (see Stein 2010; Risman 2018), which is of note since the upper bound of the NSFG sample is age 45. In this case, we might thus expect that individuals who select a non-normative sexual orientation category are, on average, younger, and will have similar self-reported sexual attractions and behaviors to individuals who identify as gay or bisexual. However, Table 1 shows that these individuals seem to be more similar to straight respondents in terms of sexual attraction and behavior. We do see some higher percentages of same-sex sexual behavior among women who reported something else/ don't know identities compared to straight women: $19.7 \%$ of women who selected something else or don't know reported having had same-sex sex, compared to just $10.2 \%$ of straight-identified women, for example. These percentages were slightly higher for men as well, in that $8.9 \%$ of men who selected something else or don't know identities reported having had same-sex sex, compared to just $2.6 \%$ of straight-identified men.

In results not shown, I analyzed the age of respondents who selected something else or don't know as a sexual identity, and found $23 \%$ of those who selected something else or don't know were between the ages of 15 to 19 , a higher proportion than the proportion of 15 to 19 year olds in the entire sample (16\%). Thus, in addition to the possibility that these individuals would prefer to identify as queer or another sexual identity that is not listed as an option (or do not wish to identify with a label at all), it could also be that they are just 
not sure of their sexual orientation and are engaging in sexual exploration to find out, or it could be that they did not understand the question - or a combination of all three.

When assessing whether there are gender differences in sexual behavior among those who identified as something else or don't know, patterns generally follow those found for straight men and women - that significantly more women than men who marked something else/don't know reported having same-sex sex sometime in their life $(19.7 \%$ versus $8.9 \%$, respectively). There were no significant differences by gender when analyzing sexual attraction levels among those who marked something else/don't know.

\subsection{Sexual Attraction and Identity among Those Reporting Same-Sex Sex in Past Year}

As several studies use recent sexual behavior as their measure of the LGB community (e.g., Badgett 1995; Berg and Lien 2002; Black et al. 2003), I further examine the sexual attraction and behavior of the sub-sample of individuals who reported having same-sex sex in the last year. Figures 1 and 2 display the self-reported sexual identities (Figure 1) and self-reported sexual attraction levels (Figure 2) among the men and women who reported having had same-sex sex in the past year.

Figure 1 shows that, among women aged 15-45 who have had same-sex sex in the past year, their sexual identities are more or less evenly distributed between straight $(34 \%)$, bisexual (39\%), and gay (25\%). In contrast, over half of men aged 15-45 who report having had same-sex sex in the past year identify as gay (56\%), while $27 \%$ identify as bisexual and $15 \%$ identify as straight. Similarly, when looking at sexual attraction among men aged 15-45 who report having had same-sex sex in the last year (Figure 2), about $44 \%$ report only being attracted to the same sex, compared to just $17 \%$ of women who report the same. These gender differences are quite compelling - among those aged

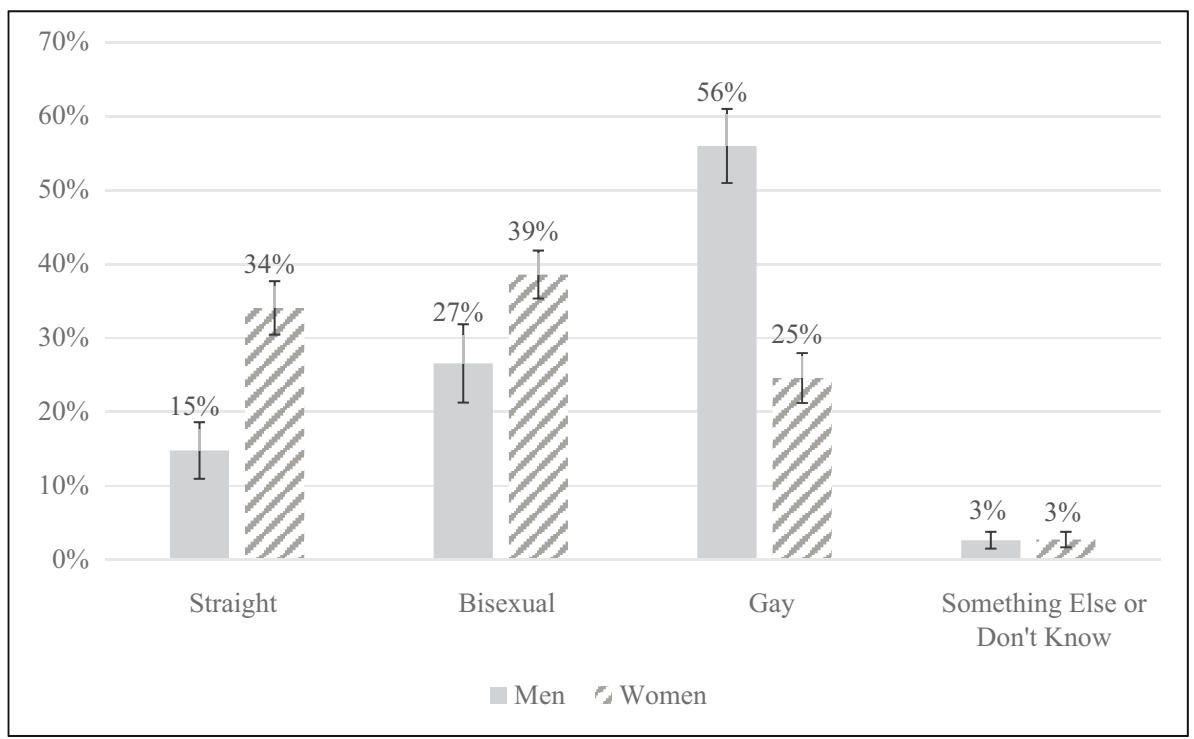

Fig. 1. Self-reported sexual identity among U.S. men and women aged 15-45 who reported having same-sex sex in the last year $(n=2,392)$.

Note: Bars indicate $95 \%$ confidence intervals. 


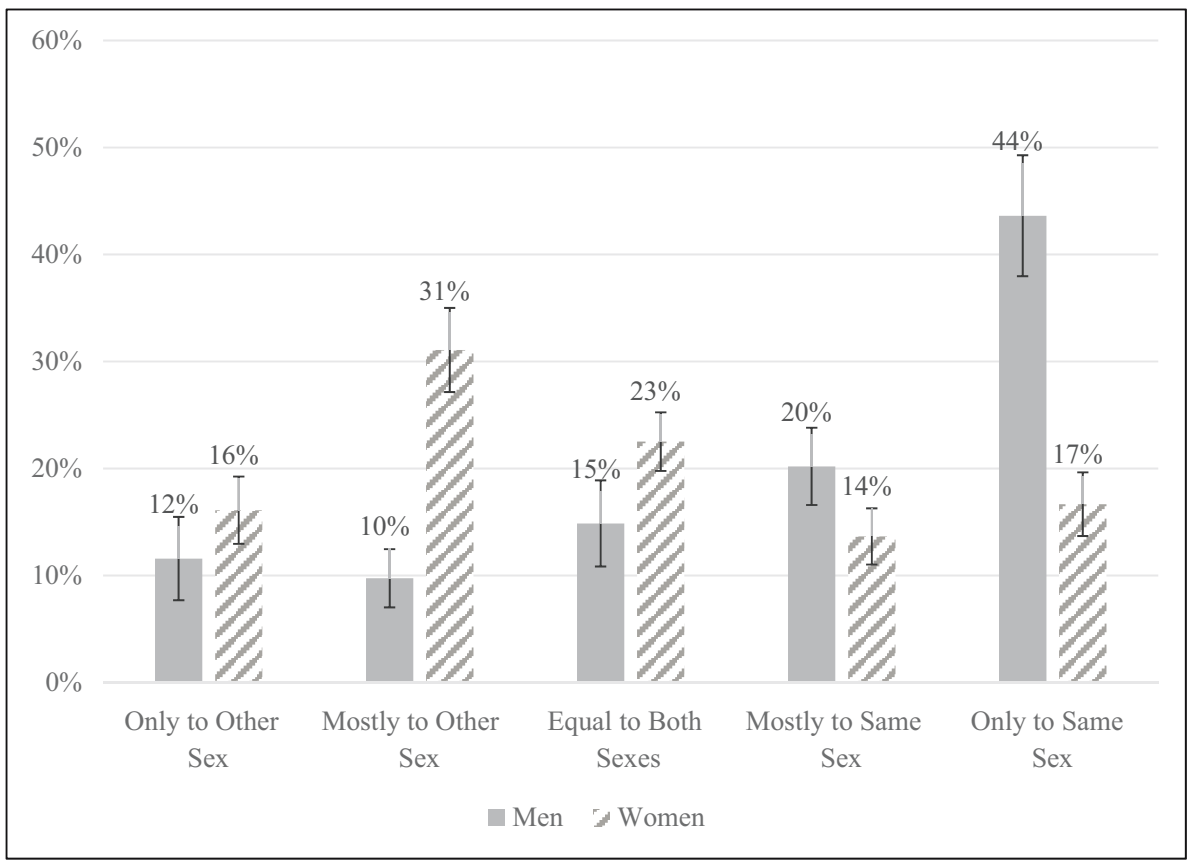

Fig. 2. Self-reported sexual attraction among U.S. men and women aged 15-45 who reported having same-sex sex in the last year $(n=2,337)$.

Note: Bars indicate $95 \%$ confidence intervals.

15-45 who report having had same-sex sex in the past year, women's sexual identity and attraction levels are much more evenly distributed among the straight, bisexual, and gay identity categories, as well as all attraction categories. In contrast, the majority of men who have had sex with men in the past year identify as gay and report only same-sex attraction. Generally speaking, results displayed in Figures 1 and 2 are striking: among U.S. men and women age 15-45 who have recently had same-sex sex, their self-reported sexual identity and attraction levels vary greatly.

\subsection{Combining Measures: Identity, Attraction, Behavior}

My analysis on how sexual identity, attraction, and behavior relate to each other allows me to assess what estimates for the LGB population in the United States may look like (for those age 15-45); if not solely based on sexual identity questions, but rather, if they were based on individuals who had checked at least one of the following: gay or bisexual identity, same-sex sex in the last year, or any same-sex attraction. Using this combination of measurement, 6,277 women in the sample (about 20\%) reported at least one of the following: gay or bisexual identity, same-sex sex in the last year, or some level of samesex attraction, and 2,470 men in the sample (about 10\%) also reported at least one of the three measures. Thus, of those aged 15-45, about $20 \%$ of women and about $10 \%$ of men would comprise the LGB community if it were defined to include all individuals who report a non-heterosexual identity, any same-sex attraction, and/or sex with a same-sex partner in the last year. This is much higher than the observed $6.4 \%$ of women and $3.6 \%$ of men aged 15-45 who self-identify as gay or bisexual. 


\subsection{Predicting Gay or Bisexual Identity from Regressions with Controls}

Next, I plot the predicted probabilities for identifying as bisexual (Figure 3) or gay (Figure 4) from self-reported sexual attraction and various sexual behaviors. Predicted probabilities are calculated from logistic regression models that predict either gay or bisexual identity from sexual attraction levels and various sexual behaviors. All models include sociodemographic controls (see Supplemental material Table A-1 for a description of all control variables used, and please see Tables A-2 and A-3 for logistic regression results).

Figures 3 and 4 show that predicted probabilities for identifying as gay or bisexual based on sexual attraction are quite similar for men and women. Specifically, men and women age 15-45 who report equal attraction to both sexes have about a $75 \%$ chance of identifying as bisexual (Figure 3), while men and women age 15-45 who report only same-sex attraction have just under a $90 \%$ chance of identifying as gay (Figure 4). The distributions of the predicted values are also about what we would expect to see in terms of how self-reported sexual attraction predicts gay and bisexual identity: the highest probability for bisexual identity is attraction to both sexes, while the highest probability for gay identity is only same-sex attraction, for both men and women.

While results are similar for men and women when examining how sexual attraction predicts sexual identity, there are clear gender differences when examining how sexual behavior predicts sexual identity for men and women age 15-45. For example, Figure 3 shows that women age 15-45 who report only same-sex sex in the last year have about a

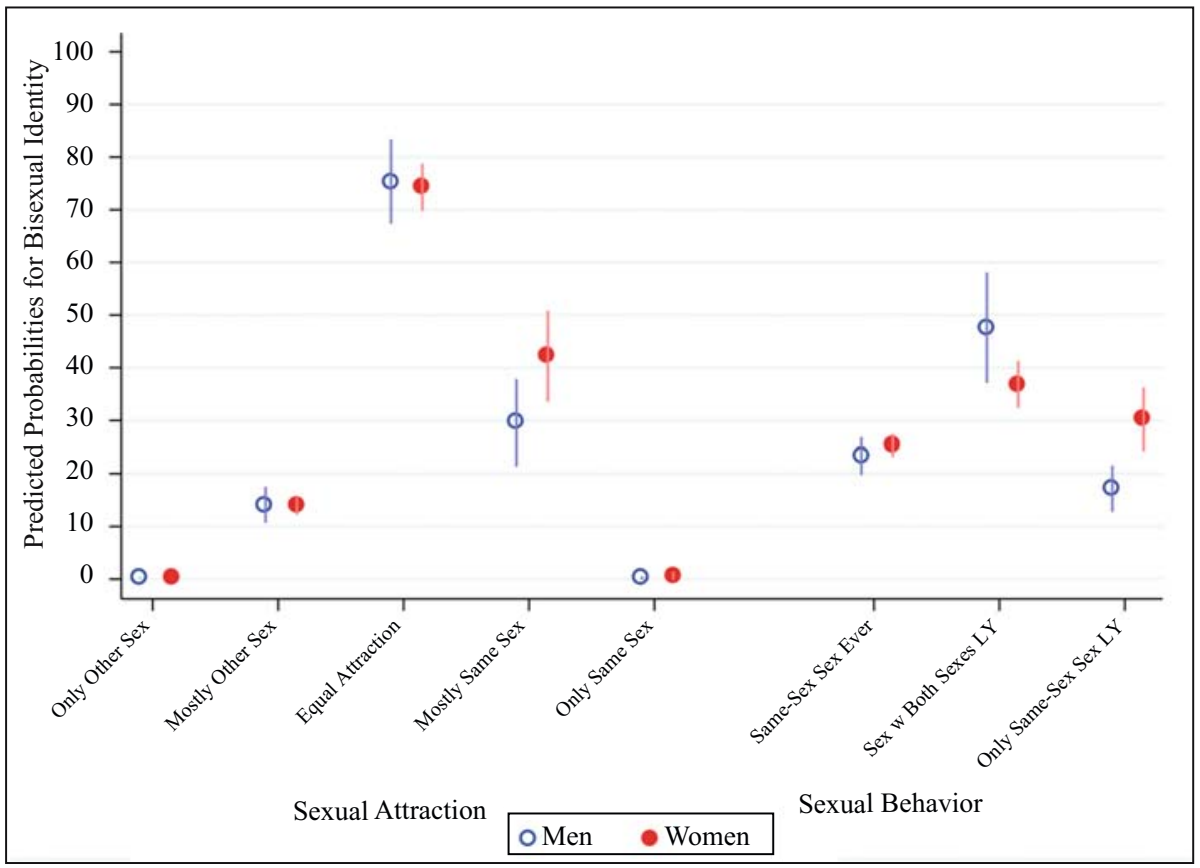

Fig. 3. Predicted probabilities for bisexual identity among U.S. men and women age 15-45.

Note: Predicted probabilities correspond to logistic regressions and have been adjusted for race, age, mother's education, immigrant status, MSA, and survey wave. Bars indicate 95\% confidence intervals. LY is Last Year. 


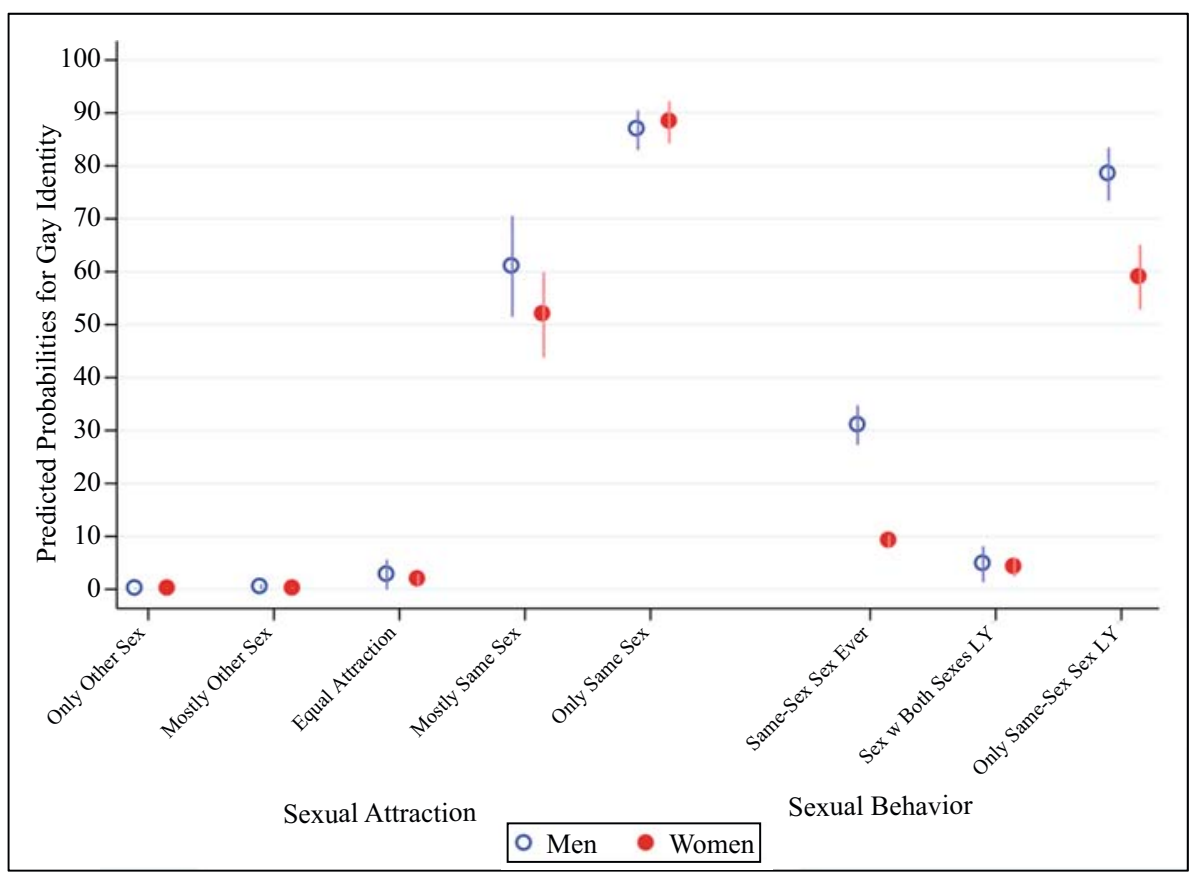

Fig. 4. Predicted probabilities for gay identity among U.S. men and women age 15-45.

Note: Predicted probabilities correspond to logistic regressions and have been adjusted for race, age, mother's education, immigrant status, MSA, and survey wave. Bars indicate 95\% confidence intervals. LY is Last Year.

$30 \%$ chance of identifying as bisexual, while men age 15-45 who report only same-sex sex in the last year have only about a $17 \%$ chance of identifying as bisexual. We also see a large difference between men and women in Figure 4 predicting gay identity, in whether they have ever had same-sex sex, and whether they have had only same-sex sex in the last year; probabilities for men are much higher than for women in both cases. Specifically, women age 15-45 who report only same-sex sex in the last year have about a $60 \%$ chance of identifying as gay, while men age 15-45 who report only same-sex sex in the last year have about an $80 \%$ chance of identifying as gay. Similarly, women age 15-45 who report ever having had same-sex sex have about a $10 \%$ chance of identifying as gay, but men age 15-45 who report ever having had same-sex sex have about a $30 \%$ chance of identifying as gay. In other words, while having had same-sex sex sometime in one's life and having had only same-sex partners in the last year both have positive effects on identifying as gay for men and women, the effect is much larger for men than for women in both cases.

\section{Discussion}

\subsection{Intersections between Sexual Identity, Sexual Attraction, and Sexual Behavior}

This article pools four waves of a nationally representative dataset to examine the relationship between self-reported sexual behavior, sexual identity, and sexual attraction among U.S. Americans aged 15 to 45. Results reveal some disjunctures between the three measures. First, I find that more Americans age 15-45 report same-sex sexual experience 
and/or same-sex attraction than identify as gay or bisexual. About $15 \%$ of women and $5 \%$ of men age 15-45 report having same-sex sex sometime in their life, and about $17 \%$ of women and $7 \%$ of men age $15-45$ report some level of current same-sex attraction. This is compared to just $6.4 \%$ of women and $3.6 \%$ of men age $15-45$ who self-identify as either gay or bisexual. The finding that more men and women report same-sex sexual experience or same-sex attraction than report gay or bisexual identity is consistent with past research (e.g., Compton et al. 2015; Gates 2011; Korchmaros et al. 2013), and there may be many reasons for this. One possible reason is fear of discrimination, as much research provides causal evidence of discrimination against out LGB individuals when they seek employment (Mishel 2016; Tilcsik 2011) and apply for housing (Friedman et al. 2013). Another reason could be negative stereotypes and social stigma often associated with identifying as gay or bisexual. Research by Ward (2008) and Silva (2016) show that some men who sleep with men still choose to identify as straight, and purposely distance themselves from any sort of queer identity to construct (and reinforce) ideals of normative masculinity. Studies have also shown that out LGB individuals are sometimes viewed as less competent, less moral, less trustworthy, and less warm than straight individuals (Mize and Manago 2018a; Webster et al. 1998). In addition, a whopping 23\% of the American public still believe that gay and lesbian relations between consenting adults should be illegal (Gallup 2018). Results from these past studies suggest that fear of stigma and social penalties may be one reason that many individuals who have sex with or are attracted to those of the same sex do not take on a non-heterosexual identity.

A further reason that more Americans report same-sex sexual behavior and same-sex attraction than report gay or bisexual identity could be rejection of such labels all together. Research shows that some individuals who report engaging in same-sex sex or who report same-sex attraction also express discomfort in labeling their sexual orientation, saying that current definitions of sexual identity categories do not accurately describe them, that they find them to be restrictive, or that they prefer other identities over non-heterosexual identity labels (Budnick 2016; Diamond 2008; Savin-Williams and Vrangalova 2013). Previous research has also documented the strong heteronormative expectations and proscriptions - such as promoting gender conventionality and heterosexuality as the norm and "correct" way to be - that exist as background context in contemporary U.S. culture (e.g., Neilsen et al. 2000; Pascoe 2012), which some people may be responding to when asked to label their sexual identity, regardless of their sexual desires and history.

Findings from this study also illustrate that the extent to which sexual identity, attraction, and behavior aligns differs by gender. For example, I find that straight women age 15-45 are significantly more likely to report same-sex attraction and same-sex sexual experience than straight men of the same age. As another example, I find that gay women age 15-45 are significantly more likely to report other-sex attraction and sex with both sexes, both ever and in the last year, compared to gay men of the same age. This suggests that sexual identity may be more aligned with attraction and behavior for men than for women. It also suggests that women are more sexually fluid in terms of same-sex sex and same-sex attraction compared to men.

England et al. (2016) and Mishel et al. (forthcoming) argue that there is more same-sex sex among women than men, due to the asymmetry of the gender revolution. Specifically, 
they argue that the gender revolution sent the message that gender nonconformity was more acceptable than before; and, given that deviations from exclusive heterosexuality are seen as gender nonconforming, part of the implicit message was permission to have samesex sex. However, this message was received much more strongly by women than by men, because society continued to devalue anything seen as feminine. This meant that the gender revolution was largely a one-way street - that is, seen as less applicable to men. Thus, the social costs of any kind of gender nonconformity, including deviating from exclusive heterosexuality, decreased much more for women than for men (Mishel et al. forthcoming). What's more, many researchers have documented the strong ties between cultural notions of masculinity and of heterosexuality (e.g., Bridges 2014, Connell 1995; Connell and Messerschmidt 2005; Plummer 1999; Silva 2016; Ward 2008), which may also explain why women may be more sexually fluid in terms of same-sex sexuality compared to men. Indeed, Pascoe (2012) finds that boys in high school engage in what she terms "fag discourse," a form of gender policing where boys routinely call each other "fags" to socialize one another into performing normative masculine behaviors and to enforce their heterosexuality, while such policing is not found among girls.

Figures 3 and 4 also revealed that men's predicted probabilities of identifying as gay are significantly higher than women's if they ever have engaged in same-sex sex. Recent experimental research by Mize and Manago (2018b) may shed some light as to why this may be. Mize and Manago (2018b) show that people allow women more freedom to experiment with same-sex sex without assigning them a lesbian sexual identity, while men are not allowed this same freedom to experiment with same-sex sexuality without people perceiving them to be gay. The argument put forth is that men's - but not women's - heterosexuality is an especially privileged identity that is easily lost if engaging in same-sex sexual behavior. Along the same lines, a study by Mishel et al. (2018) analyzes Google Trends data, and finds that people turn to Google to ask whether their sons, dads, boyfriends, husbands, brothers, and other boys/men are "gay" at consistently higher rates than analogous searches regarding their daughters, moms, girlfriends, wives, sisters, or other girls/women. Mishel et al. (2018) argue that because men's heterosexuality is seen as more precarious and more difficult to uphold than women's heterosexuality, it follows that people would question the heterosexuality of men and boys in their life more frequently than the women and girls they know. My findings seem to be consistent with this theory, in that, my results illustrate that men and women self-identify in alignment with the notion that men's heterosexuality is more precarious than women's heterosexuality. I posit that, due to the growing acceptance of same-sex sexuality among women but not men, and due to the more severe consequences for men when they break gender roles or identify as anything but heterosexual (Page and Yee 1985; Pascoe 2012; Pelligrini 1992), men are less likely than women to explore engaging in same-sex sex unless they are comfortable enough to also take on a gay or bisexual identity. Additional, qualitative research would be beneficial to further explore this notion.

Next, my analysis also reveals that a sizeable portion of Americans age 15-45 select "something else" or "don't know" when asked to label their sexual identity. Most research on the LGB community will typically exclude those who do not identify with a normative sexual identity such as lesbian, gay, or bisexual - so that individuals choosing something 
else or don't know identities would be dropped from analysis. As a fraction of those who do not identify as straight, the proportion of men and women who would be dropped from analysis is quite substantial. As such, excluding those who do not choose a normative sexual identity category when conducting analysis on the LGB community or to explore measurement of the LGB population becomes problematic.

As a supplemental analysis, in results not shown, I ran the same logistic regressions with the same controls as in Supplemental material Tables A-2 and A-3 but used something else/don't know identity as the outcome variable, and then calculated predicted probabilities from these regressions. Predicted probabilities were very low for every attraction level and every sexual behavior measure (most under 3\%, for both men and women). Because it is difficult to interpret non-normative sexual identity categories, some social scientists argue for utilizing open-ended responses when asking respondents to label their sexual identity (e.g., Better and Simula 2015), as it allows respondents to use their own words when defining their sexual identities. Others have recommended simply not including "other" or "something else" as a response option for sexual identity, and that if including "don't know" as responses, to make sure to specify two options: "I don't know yet," and "I don't know what this question means" (Badgett et al. 2009; Saewyc et al. 2004). I agree that using an open-ended response may be most accurate, but note that doing so may not be the most useful to quantitative researchers, as responses may vary greatly and grouping categories may become theoretically difficult. Yet, this may also illuminate ordinarily puzzling findings in the data, such as reports of same-sex sex but no same-sex attraction, which may be explained by someone's sexual identity as asexual, for example (see Poston and Baumle 2010). I also agree with Badgett et al. (2009) and Saewyc et al. (2004) that if national surveys include "I don't know," as a response option for sexual identity, then it is imperative to clarify whether the respondent does not understand the question, or just does not know how to label their sexual identity yet.

\subsection{Measure Limitations, Recommendations, and Implications}

This research sheds light on the complexity of defining sexual orientation using one of the three commonly used measures of identity, attraction, or behavior. This section will summarize some limitations of using each measure to define the LGB population. First, using only a sexual identity measure to define the LGB community can be limiting as more Americans report same-sex sexual behavior and same-sex attraction than report gay or bisexual identity. As discussed, there may be many reasons for this, including fear of societal costs and negative social stigma, or rejection of normative sexual identity categories altogether. In this sense, using only sexual identity to define the LGB community may lead to underestimation of the LGB population.

Second, using only sexual attraction to define the LGB population can be limiting, as more people report some level of same-sex attraction than report same-sex sexual experience or non-heterosexual identity. Yet, stigma and strong heteronormative scripts in American society may discourage these individuals from ever acting on their same-sex desire. Moreover, these individuals may not feel strongly enough about their same-sex attraction to ever act on it. In this sense, using only sexual attraction to define the LGB population may lead to overestimation of this population. 
Finally, there are limitations to defining sexual orientation using only sexual behavior measures. For example, using only same-sex sexual behavior as the LGB measure omits large proportions of individuals who self-identify as gay or bisexual but who have no same-sex sexual experience. (Also, how it affects proportions depends on whether straight individuals are defined using sexual experience with other-sex partners - in this scenario, virgins would not be counted as heterosexual.) Recall that about $24 \%$ of bisexual women and about $16 \%$ of gay women aged $15-45$ report 0 lifetime same-sex sex partners, while about $37 \%$ of bisexual men and about $16 \%$ of gay men aged $15-45$ report 0 lifetime samesex sex partners. Indeed, this phenomenon is also seen when analyzing sexual behaviors of Australian men and women aged 16-69, though percentages are slightly lower: 17\% of Australian bisexual men and 9\% of Australian bisexual women report 0 same-sex sex partners, as do $3 \%$ of Australian gay men and $4 \%$ of Australian gay women (Richters et al. 2014).

One reason that large proportions of self-identified gay and bisexual respondents have never had same-sex sex could be due to stigma around having same-sex sexual relations, as different moral and social implications come with homosexuality (Herek 2009); another reason could simply be due to a lack of access to other non-heterosexuals to date (Ghaziani 2014; Rosenfeld and Thomas 2012). In any case, the lack of same-sex sexual experience among some self-identified bisexual and gay individuals age 15-45 in the United States is important to note, as it suggests that measuring the LGB community using only sexual behavior may lead to underestimation of the LGB population. On the other hand, using this measure alone may incorrectly count self-reported straight individuals who have had same-sex sexual experiences for experimentation purposes in the past but no longer do so, or have no intention of doing so in the future - which may lead to overestimating the size of the LGB community. In this sense, it is difficult to say whether using only measures of sexual behavior to define the LGB community would lead to over- or underestimation of this population. Another consideration is whether to use recent sexual behavior or lifetime sexual behavior; lifetime behavior typically produces larger estimates, but recent behavior may be more accurate if seeking to assess the LGB community's current reach.

Because of these limitations, deciding which measure to use to define the LGB population in quantitative analyses can be a very difficult decision. Some researchers argue that recent sexual behavior is the best measure (Black et al. 2003); others argue that sexual attraction is the best measure, if limited to a single measure and analysis is on adolescents (Saewyc et al. 2004); others argue for a combination of the three measures (e.g., Baumle et al. 2009; Laumann et al. 1994); and yet other researchers argue that the specific research question should drive the measure (Compton et al. 2015). I agree with Compton et al. (2015): the specific measure of sexuality used in research on the LGB community should depend on the study's research question. After all, using a sexual behavior measure may be most appropriate for studies interested in examining sexually transmitted infections among sexual minorities, while it may be more appropriate to use a combination of sexual orientation measures for researchers interested in political and social change (Compton et al. 2015). Thus, social scientists interested in this topic should let their research question drive their measure of sexual orientation, while being transparent and clear about the measure they use to indicate LGB identity, and address any potential limitations of their measure of choice. If the research question does not strongly 
justify using one measure over another, researchers should consider conducting the same analysis using more than one measure or using multiple measures combined (if the data allow them to), and address if and how results vary based on how they define the LGB community. After all, previous studies show differences in findings based on the measure of sexual orientation used. For example, Bostwick et al. (2010) find that identifying as LGB is associated with higher odds of anxiety disorders compared to identifying as straight, for both men and women; however, they also find that women who report only same-sex sex partners in their lifetime had the lowest rates of most disorders. As another example, Compton et al. (2015) find that, if using a behavior dimension of sexual orientation, bisexual men self-report as significantly less healthy compared to straight men; however, they find no significant differences in self-reported health between bisexual men and straight men when using an attraction or identity measure of sexual orientation.

As for what measure(s) to use to best assess the size of the LGB community, it ultimately depends on how one defines the "LGB community." As discussed, using sexual identity as the barometer of interest for the LGB population can be limiting, as fear of discrimination, stigma around non-heterosexual identity, prominence of heteronormative social scripts, and/or rejection of sexual identity labels may influence individuals who engage in same-sex sex or who feel same-sex attraction to not explicitly take on an LGB identity, which may translate to not marking it on a survey. In this sense, using multiple measures to assess the LGB population may be the most useful in calculating its reach. As such, this research allowed me to assess what the estimate for the LGB population may look like for those aged 15-45 if using a combination of sexual identity, behavior, and attraction. Specifically, I assessed what it would look like if estimates were based on individuals who checked at least one of the following: gay or bisexual identity, same-sex sexual behavior in the past year, or any same-sex attraction. Using this combination of measurement, I find that about $20 \%$ of women and $10 \%$ of men would comprise the LGB community (among those aged 15-45). This is much higher than the $6.4 \%$ of women and $3.6 \%$ of men aged 15-45 who self-identify as gay or bisexual.

In general, understanding how sexual attraction, sexual behavior, and sexual identity are linked is an important aspect of sexuality research and research on the LGB community. The disjunctures between self-reports of non-heterosexual identity, same-sex sexual behavior, and same-sex attraction among men and women age 15-45 in the United States that this study finds have implications for the current methods of measurement for the size of the LGB community - measurement that is critical as these figures inform a host of public policies, human rights issues, and anti-discrimination laws.

One limitation of this analysis is that there are no individuals above the age of 45 , which motivates further research on the links between sexual identity, attraction, and behavior among U.S. adults older than 45. In any case, results from this analysis suggest that researchers should be open to more complex definitions of sexuality. In this regard, there has been increasing interest among social scientists to explore and analyze sexual identities and measures that exist on the borders of heterosexuality and homosexuality, such as queer, asexual, pansexual, fluid, or heteroflexible (Bridges 2014; Callis 2014; Compton et al. 2015; Savin-Williams and Vrangalova 2013; Silva 2016; Ward 2008). In general, more research is needed to fully understand whether estimates of health and wellbeing disparities, inequalities, and victimization of LGB individuals differ according to 
the measure of sexual orientation that is used, as oftentimes, researchers do not have a choice in this decision when using existing secondary data. Because of the disjunctures between the three measures, and the fact that more men and women age 15-45 report same-sex attraction and same-sex sexual behavior than identify as gay or bisexual, it is important for surveys to ask other measures of sexual orientation rather than just identity (such as attraction or behavior), and for researchers to utilize multiple measures whenever appropriate, in order to obtain more accurate and all-encompassing analysis on the LGB community.

\section{References}

Baumle, A.K., D’Lane Compton, and D.L. Poston. 2009. Same Sex Partners: The Demography of Sexual Orientation. Albany, NY: SUNY Press.

Baumle, A.K. and D.L. Poston. 2011. "The Economic Cost of Homosexuality: Multilevel Analyses." Social Forces 89(3): 1005-1031. DOI: https://doi.org/10.1093/sf/ 89.3.1005.

Betts, P. 2009. "Developing Survey Questions on Sexual Identity: Cognitive/In-Depth Interviews." Office for National Statistics. Available at: https://www.ons.gov.uk/file? uri=/methodology/classificationsandstandards/sexualidentityguidanceandprojectdocumentation/sexidcogreportfinal_tcm77-181190.pdf (accessed October 2019).

Badgett, M.V.L. 1995. "The Wage Effects of Sexual Orientation.” ILR Review 48(4): 726-739. DOI: https://doi.org/10.1177/001979399504800408.

Badgett, M.V.L. and Sexual Minority Assessment Research Team (SMART). 2009. "Best Practices for Asking Questions about Sexual Orientation on Surveys." UCLA: The Williams Institute. Available at: https://escholarship.org/uc/item/706057d5 (accessed October 2019).

Berg, N. and D. Lien. 2002. "Measuring the Effect of Sexual Orientation on Income: Evidence of Discrimination?" Contemporary Economic Policy 20(4): 394-414. DOI: https://doi.org/10.1093/cep/20.4.394.

Better, A. and B.L. Simula. 2015. "How and for Whom Does Gender Matter? Rethinking the Concept of Sexual Orientation.” Sexualities 18(56): 665-680. DOI: https://doi.org/ $10.1177 / 1363460714561716$.

Black, D., G. Gates, S. Sanders, and L. Taylor. 2002. "Why Do Gay Men Live in San Francisco?" Journal of Urban Economics: 54-76. DOI: https://doi.org/10.1006/ juec.2001.2237.

Black, D.A., H.R. Makar, S.G. Sanders, and L.J. Taylor. 2003. "The Earnings Effects of Sexual Orientation.” Industrial and Labor Relations Review 56(3): 449-469. DOI: https://doi.org/10.1177/001979390305600305.

Black, D., G.J. Gates, S.G. Sanders, and L. Taylor. 2007. "The Measurement Error of Same-Sex Unmarried Partner Couples in the U.S. Census." California Center for Population Research.

Bostwick, W.B., C.J. Boyd, T.L. Hughes, and S. Esteban McCabe. 2010. "Dimensions of Sexual Orientation and the Prevalence of Mood and Anxiety Disorders in the United States." American Journal of Public Health 100(3): 468-475. DOI: https://doi.org/ 10.2105/AJPH.2008.152942. 
Bridges, T. 2014. “A Very 'Gay' Straight? Hybrid Masculinities, Sexual Aesthetics, and the Changing Relationship between Masculinity and Homophobia." Gender and Society 28(1): 58-82. DOI: https://doi.org/10.1177/0891243213503901.

Bridges, T. and M. Moore. 2018. "Young Women of Color and Shifting Sexual Identities." Contexts 18: 86-88. DOI: https://doi.org/10.1177/1536504218767125.

Budnick, J. 2016. “'Straight Girls Kissing'?: Understanding Same-Gender Sexuality beyond the Elite College Campus." Gender \& Society 30(5): 1-24. DOI: https://doi.org/10.1177/0891243216657511.

Busseri, M., T. Willoughby, H. Chalmers, and A. Bogaert. 2006. "Same-sex attraction and successful adolescent development." Journal of Youth and Adolescence 35: 563-575. DOI:https://doi.org/10.1007/s10964-006-9071-4.

Callis, A.S. 2014. "Bisexual, pansexual, queer: Non-binary identities and the sexual borderlands." Sexualities 17(1/2): 63-80. DOI: https://doi.org/10.1177/1363460 713511094.

Carpenter, C. 2009. "Sexual Orientation and Outcomes in College." Economics of Education Review 28: 693-703. DOI: https://doi.org/10.1016/j.econedurev.2007. 10.010 .

Carpenter, C.S. and S.T. Eppink. 2017. "Does It Get Better? Recent Estimates of Sexual Orientation and Earnings in the United States." Southern Economic Journal 84(2): 426-441. DOI: http://doi.wiley.com/10.1002/soej.12233.

Centers for Disease Control. 2018. "About the National Survey of Family Growth." Available at: https://www.cdc.gov/nchs/nsfg/about_nsfg.htm (accessed November 2018).

Chandra, A., W.D. Mosher, C. Copen, and C. Sionean. 2011. "Sexual behavior, sexual attraction, and sexual identity in the United States: Data from the 2006-2008 National Survey of Family Growth." National health statistics reports; no 36. Hyattsville, MD: National Center for Health Statistics. DOI: https://doi.org/ 10.1007/978-94-007-5512-3_4.

Cochran, S.D., J.G. Sullivan, and V.M. Mays. 2003. "Prevalence of mental disorders, psychological distress, and mental health services use among lesbian, gay, and bisexual adults in the United States." Journal of consulting and clinical psychology 71(1): 53-61. DOI: http://dx.doi.org/10.1037/0022-006X.71.1.53.

Compton, D.R., D.N. Farris, and Y-T. Chang. 2015. "Patterns of Bisexuality in America." Journal of Bisexuality 15: 481-497. DOI: https://doi.org/10.1080/15299716.2015. 1048919.

Connell, R.W. 1995. Masculinities. Cambridge, UK: Polity Press.

Connell, R.W. and J.W. Messerschmidt. 2005. Hegemonic masculinity: Rethinking the concept. Gender \& Society 19: 829-859. DOI: https://doi.org/10.1177/089124320 5278639.

Copen, C., A. Chandra, and I. Febo-Vazquez. 2016. "Sexual behavior, sexual attraction, and sexual orientation among adults aged 18-44 in the United States: Data from the 2011-2013 National Survey of Family Growth." National health statistics reports; no 88. Hyattsville, MD: National Center for Health Statistics Available at: https://www.ncbi.nlm.nih.gov/pubmed/26766410 (accessed October 2019). 
DeMaio, T.J., N. Bates, and M. O’Connell. 2013. "Exploring Measurement Error Issues in Reporting of Same-Sex Couples.” Public Opinion Quarterly 77(S1): 145-158. DOI: https://doi.org/10.1093/poq/nfs066.

Diamond, L. 2008. "Female Bisexuality from Adolescence to Adulthood: Results from a 10-Year Longitudinal Study." Developmental Psychology 44(1): 5-14. DOI: http://dx. doi.org/10.1037/0012-1649.44.1.5.

England, P., E. Mishel, and M.L. Caudillo. 2016. "Increases in Sex with Same-Sex Partners and Bisexual Identity Across Cohorts of Women (but Not Men)." Sociological Science 3: 951-970. DOI: https://doi.org/10.15195/v3.a42.

Epstein, R., P. MckInney, S. Fox, and C. Garcia. 2012. "Support for a fluid-continuum model of sexual orientation: A large-scale internet study." Journal of Homosexuality 59(10): 1356-1381. DOI: https://doi.org/10.1080/00918369.2012.724634.

Fischer, M.M. 2016. "Identifying same-sex couples in cross-national survey data: a comparison of same-sex couples' demographic and socio-economic traits in six European countries." In Nederland in context: verschillen en overeenkomsten, edited by R. Meuleman, G. Kraaykamp, and M. Wittenberg, 50-79. Den Haag: DANS.

Friedman, S., A. Reynolds, S. Scovill, F. Brassier, R. Campbell, and M. Ballou. 2013. “An Estimate of Housing Discrimination against Same-Sex Couples.” Prepared for U.S. Department of Housing and Urban Development. DOI: http://dx.doi.org/10.2139/ssrn. 2284243.

Gallup. 2018. "Gay and Lesbian Rights.” Retrieved November 2018. Available at: http:// www.gallup.com/poll/1651/gay-lesbian-rights.aspx (accessed October 2019).

Gates, G. 2011. "How Many People are Lesbian, Gay, Bisexual, and Transgender?" Williams Institute Report. Available at: https://escholarship.org/uc/item/09h684X2 (accessed October 2019).

Gavrilets, S. and W.R. Rice. 2006. "Genetic models of homosexuality: generating testable predictions." Proceedings of the Royal Society B: Biological Sciences 273(1605): 3031-3038. DOI: https://doi.org/10.1098/rspb.2006.3684.

Geary, R.S., C. Tanton, B. Erens, S. Clifton, P. Prah, K. Wellings, K.R. Mitchell, J. Datta, K. Gravningen, E. Fuller, A.M. Johnson, P. Sonnenberg, and C.H. Mercer. 2018. "Sexual identity, attraction and behaviour in Britain: The implications of using different dimensions of sexual orientation to estimate the size of sexual minority populations and inform public health interventions." PLOS One. 13(1): e0189607: 3, 7, 9. DOI: https://doi.org/10.1371/journal.pone.0189607.

Ghaziani, A. 2014. There Goes the Gayborhood? Princeton University Press.

Hamilton, L. 2007. “Trading on Heterosexuality: College Women's Gender Strategies and Homophobia." Gender \& Society 21: 145-172. DOI: https://doi.org/10.1177/ 0891243206297604.

Harper, G. 2007. "Sex isn't that simple: Culture and context in HIV prevention interventions for gay and bisexual male adolescents." American Psychologist 62(8): 806-819. DOI: http://dx.doi.org/10.1037/0003-066X.62.8.806.

Herek, G. 2009. "Sexual Stigma and Sexual Bias in the US: A Conceptual Framework." Contemporary Perspectives on Lesbian, Gay, and Bisexual Identities 54: 183-195. DOI: https://doi.org/10.1007/978-0-387-09556-1_4. 
Igartua, K., B. Thombs, G. Burgos, and R. Montoro. 2009. "Concordance and discrepancy in sexual identity, attraction, and behavior among adolescents." Journal of Adolescent Health 45(6): 602-608. DOI: https://doi.org/10.1016/j.jadohealth.2009.03.019.

Kinsey, A., W. Pomeroy, and C. Martin. 1953. Sexual Behavior in the Human Female. Philadelphia, PA: WB Saunders.

Korchmaros, J., C. Powell, and S. Stevens. 2013. "Chasing Sexual Orientation: A Comparison of Commonly Used Single-Indicator Measures of Sexual Orientation." Journal of Homosexuality 60: 596-614. DOI: https://doi.org/10.1080/ 00918369.2013.760324.

Laumann, E.O., J. Gagnon, R. Michael, and S. Michaels. 1994. The social organization of sexuality: Sexual practices in the United States. Chicago, IL: University of Chicago Press.

Mishel, E. 2016. "Discrimination against Queer Women in the U.S. Workforce: A Résumé Audit Study." Socius: Sociological Research for a Dynamic World 2: 1-13. DOI: https://doi.org/10.1177/2378023115621316.

Mishel, E., P. England, J. Ford, and M.L. Caudillo. Forthcoming. "Cohort Increases in Sex with Same-Sex Partners: Do Trends Vary by Gender, Race, and Class?" Gender \& Society.

Mishel, E., T. Bridges, and M.L. Caudillo. 2018. "Google, Tell Me. Is He Gay?: Masculinity, Homophobia, and Gendered Anxieties in Google Search Queries about Sexuality." SocArXiv. November 7. DOI: https://doi.org/10.31235/ osf.io/4se75.

Mize, T.D. 2016. "Sexual Orientation in the Labor Market." American Sociological Review 81(6): 1132-1160. DOI: https://doi.org/10.1177/0003122416674025.

Mize, T.D. and B. Manago. 2018a. "The Stereotype Content of Sexual Orientation." Social Currents: 1-21. DOI: https://doi.org/10.1177/2329496518761999.

Mize, T.D. and B. Manago. 2018b. "Precarious Sexuality: How Men and Women Are Differentially Categorized for Similar Sexual Behavior." American Sociological Review. DOI: https://doi.org/10.1177/0003122418759544.

Neilsen, J.M., G. Walden, and C.A. Kunkel. 2000. "Gendered Heteronormativity: Empirical Illusions in Everyday Life." Sociological Quarterly 41(2): 283-296. DOI: https://doi.org/10.1111/j.1533-8525.2000.tb00096.x.

O'Connell, M. and G. Gooding. 2006. "The Use of First Names to Evaluate Reports of Gender and Its Effect on the Distribution of Married and Unmarried Couple Households." Paper presented at the Population Association of America Meeting, Date: 3/30/06, Place: Los Angeles, U.S.A. Avaliable at: https://paa2006.princeton. edu/papers/60208 (accessed October 2019).

O’Reilly, J.M., M.L. Hubbard, J. Lessler, P. Biemer, and C. Turner. 1994. “Audio and Video Computer Assisted Self-Interviewing: Preliminary Tests of New Technologies for Data Collection.” Journal of Official Statistics 10(2): 197-214. Available at: https://www.ncbi.nlm.nih.gov/pmc/articles/PMC3279921/ (accessed October 2019).

Page, S. and M. Yee. 1985. "Conception of Male and Female Homosexual Stereotypes among University Undergraduates." Journal of Homosexuality 12: 109-118. DOI: https://doi.org/10.1300/J082v12n01_06. 
Pascoe, C.J. 2012. Dude You're a Fag: Masculinity and Sexuality in High School. Los Angeles, CA: University of California Press.

Pathela, P., A. Hajat, J. Schillinger, S. Blank, R. Sell, and F. Mostashari. 2006. "Discordance between Sexual Behavior and Self-Reported Sexual Identity: A Population-Based Survey of New York City Men." Annals of Internal Medicine 145: 416-425. DOI: https://doi.org/10.7326/0003-4819-145-6-200609190-00005.

Pelligrini, A. 1992. S(h)ifting the terms of Hetero/sexism: Gender, power, homophobia." In Homophobia: How We All Pay the Price, edited by W.J. Blumenfeld, 39-56. Boston: Beacon Press.

Plummer, D. 1999. One of the boys: Masculinity, homophobia, and modern manhood. New York: Harrington Park Press.

Poston, D.L. and A.K. Baumle. 2010. "Patterns of Asexuality in the United States." Demographic Research 23(18): 509-530. DOI: https://doi.org/10.4054/DemRes. 2010.23.18.

Richters, J., D. Altman, P.B. Badcock, A.M.A. Smith, R.O. de Visser, A.E. Grulich, C. Rissel, and J.M. Simpson. 2014. "Sexual identity, sexual attraction and sexual experience: the Second Australian Study of Health and Relationships." Sexual Health 11: 451-460. DOI: https://doi.org/10.1071/SH14117.

Risman, B.J. 2018. Where the Millennials Will Take Us. Oxford University Press.

Rosenfeld, M.J. and R.J. Thomas. 2012. "Searching for a Mate: The Rise of the Internet as a Social Intermediary." American Sociological Review 77(4): 523-547. DOI: https://doi.org/10.1177/0003122412448050.

Rupp, L., V. Taylor, S. Regev-Messalem, Alison Fogarty, and Paula England. 2014. "Queer Women in the Hookup Scene: Beyond the Closet?" Gender \& Society 28: 212-235. DOI: https://doi.org/10.1177/0891243213510782.

Saewyc, E.M., G. Bauer, C. Skay, L. Bearinger, M. Resnick, E. Reis, and A. Murphy. 2004. "Measuring sexual orientation in adolescent health surveys: Evaluation of eight school-based surveys." Journal of Adolescent Health 35(345): 1-15. DOI: https://doi.org/10.1016/j.jadohealth.2004.06.002.

Savin-Williams, R. and Z. Vrangalova. 2013. "Mostly Heterosexual as a Distinct Sexual Orientation Group: A Systematic Review of the Empirical Evidence." Developmental Review 33(1): 58-88. DOI: https://doi.org/10.1016/j.dr.2013.01.001.

Silva, T. 2016. "Bud-Sex: Constructing Normative Masculinity among Rural Straight Men That Have Sex With Men.” Gender \& Society XX(X): 1-23. DOI: https://doi.org/ 10.1177/0891243216679934.

Smith, A., C. Rissel, J. Richters, A. Grulich, and R. de Visser. 2003. "Sex in Australia: Sexual identity, sexual attraction and sexual experience among a representative sample of adults." Australian and New Zealand Journal of Public Health 27(2): 138-145. DOI: https://doi.org/10.1111/j.1467-842X.2003.tb00801.x.

Stein, A. 2010. "The Incredible Shrinking Lesbian World and Other Queer Conundra." Sexualities 13(1): 21-32. DOI: https://doi.org/10.1177/1363460709352724.

Tilcsik, A. 2011. "Pride and Prejudice: Employment Discrimination against Openly Gay Men in the United States." American Journal of Sociology 117(2): 586-626. DOI: https://doi.org/10.1086/661653. 
Tourangeau, R. and T.W. Smith. 1996. "Asking Sensitive Questions: The Impact of Data Collection Mode.” Question Format, and Question Context. Public Opinion Quarterly 60: 275-304. DOI: https://doi.org/10.1086/297751.

Villarroel, M.A., C.F. Turner, E. Eggleston, A. Al-Tayyib, S.M. Rogers, A.M. Roman, P.C. Cooley, and H. Gordek. 2006. "Same-Gender Sex in the United States: Impact of T-Acasi on Prevalence Estimates." Public Opinion Quarterly 70(2): 166-196. DOI: https://doi.org/10.1093/poq/nfj023.

Ward, J. 2008. "Dude-sex: White masculinities and 'authentic' heterosexuality among dudes who have sex with dudes." Sexualities 11(4): 414-434. DOI: https://doi.org/ $10.1177 / 1363460708091742$.

Webster, M., S.J. Hysom, and E.M. Fullmer. 1998. "Sexual Orientation and Occupation as Status." Advances in Group Processes 15: 1-21.

Wellings, K., J. Field, A. Johnson, and J. Wadsworth. 1994. Sexual Behavior in Britain: The National Survey of Sexual Attitudes and Lifestyles. Penguin Books.

Received March 2018

Revised November 2018

Accepted May 2019 